\title{
Health-related quality of life issues, including symptoms, in patients with active COVID-19 or post COVID-19; a systematic literature review
}

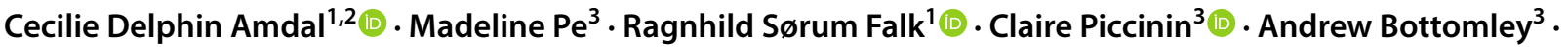

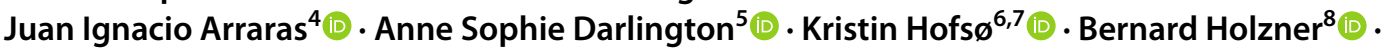

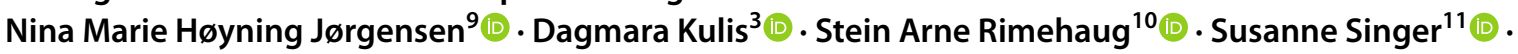 \\ Katherine Taylor ${ }^{11}$ (i) . Sally Wheelwright ${ }^{12}$ (D) Kristin Bjordal $^{1,13}$ (D)
}

Accepted: 7 June 2021 / Published online: 19 June 2021

(c) The Author(s) 2021

\begin{abstract}
Purpose This systematic review was performed to identify all relevant health-related quality of life (HRQoL) issues associated with COVID-19.

Methods A systematic literature search was undertaken in April 2020. In four teams of three reviewers each, all abstracts were independently reviewed for inclusion by two reviewers. Using a pre-defined checklist of 93 criteria for each publication, data extraction was performed independently by two reviewers and subsequently compared and discussed. If necessary, a third reviewer resolved any discrepancies. The search was updated in February 2021 to retrieve new publications on HRQoL issues including issues related to the long-term consequences of COVID-19.

Results The search in April 2020 identified 3342 potentially relevant publications, and 339 publications were selected for full-text review and data extraction. We identified 75 distinct symptoms and other HRQoL issues categorized into 12 thematic areas; from general symptoms such as fever, myalgia, and fatigue, to neurological and psychological issues. The updated search revealed three extra issues experienced during active disease and long-term problems with fatigue, psychological issues and impaired cognitive function.

Conclusion This first comprehensive systematic review provides a detailed overview of the wide range of HRQoL issues experienced by patients with COVID-19 throughout the course of the disease. It demonstrates the devastating impact of the disease and provides critically important information for clinicians, to enable them to better recognize the disease and to provide knowledge important for treatment and follow-up. The results provided the foundation for the international development of a COVID-19 specific patient-reported HRQoL questionnaire.
\end{abstract}

Keywords COVID-19 $\cdot$ Health-related quality of life $\cdot$ Symptoms $\cdot$ Concerns $\cdot$ Patient-reported outcome

Cecilie Delphin Amdal

cecia@ous-hf.no

1 Research Support Services, Oslo University Hospital, Sogn Arena, Nydalen, Post Box 4950, Oslo, Norway

2 Department of Oncology, Oslo University Hospital, Oslo, Norway

3 Quality of Life Department, EORTC, Brussels, Belgium

4 Servicio de Navarro de Salud, Pamplona, Spain

5 School of Health Sciences, University of Southampton, Southampton, UK

6 Department of Research and Development, Oslo University Hospital, Oslo, Norway
7 Lovisenberg Diaconal University College, Oslo, Norway

8 University Hospital of Psychiatry II, Medical University of Innsbruck, Innsbruck, Austria

9 Medical Library at Oslo University Hospital, University of Oslo Library, Oslo, Norway

10 Sunnaas Rehabilitation Hospital, Nesoddtangen, Norway

11 Institute of Medical Biostatistics, Epidemiology and Informatics, University Medical Centre of Johannes Gutenberg University Mainz, Mainz, Germany

12 Health Sciences, University of Southampton, Southampton, UK

13 Faculty of Medicine, University of Oslo, Oslo, Norway 


\section{Plain English summary}

This literature review provides the first overview of the health-related quality of life issues experienced by patients with COVID-19, throughout the disease and in the early recovery phase. Although many scientific papers have reported on specific groups of symptoms, a full picture has been missing. In this systematic review, the results from studies in all continents demonstrate that patients with this disease experience a wide range of different symptoms and concerns over the course of the disease. Patients with symptoms from Covid-19 commonly presented with fever, muscle pain, cough, shortness of breath and diarrhoea. Rare symptoms such as hair loss, skin problems, painful urination, nerve pain and tightness of the chest were also reported. Patients in rehabilitation after the acute COVID19 period, experienced ongoing problems with extreme tiredness (fatigue), psychological issues and impaired mental function. Most organ systems can be affected, and the disease may have a devastating impact on the patients' health-related quality of life. COVID-19 affects people of all ages, and the symptom burden may also give reduced working abilities and societal challenges. This important information can aid clinicians to better recognize the disease and provides important knowledge for treatment and follow-up. The results will be used in the development of a questionnaire assessing these issues in future patient populations. For patients with COVID-19 and their next of kin, this will provide greater insight into many different clinical aspects of the disease and may support self-management.

\section{Introduction}

At the end of 2019, a cluster of pneumonia caused by a new beta-coronavirus, SARS coronavirus 2 (SARSCoV-2), was reported in Wuhan, Hubei Province, China [1]. As this coronavirus-induced disease (COVID-19) has recently emerged, it is of paramount importance to get a systematic overview of the patient's experiences related to the disease trajectory. As potential therapeutics and vaccines has been developed and tested, it is increasingly important to understand the virus' burden and its impact on health-related quality of life (HRQoL).

HRQoL is usually defined as a multidimensional concept [2]. It is subjective and best assessed by the patients themselves using patient-reported outcome measures (PROMs). Questionnaires which have been created to quantify HRQoL usually include measurements of the patient's physical, psychological and social functioning, in addition to symptoms of disease and treatment [3]. In the first month of the pandemic, systematic reports on patient-reported outcomes of the COVID-19 were scarce. Although, there were increasing numbers of case histories and individual descriptions of patient experiences demonstrating the devastating nature of the disease, there were no COVID-19 specific questionnaires available and researchers who wanted to include PROMs in their studies had to settle for generic instruments or symptom checklist [4, 5].

Understanding the issues that COVID-19 patients face during various stages of the disease may inform diagnosis and prognosis, and provide important indicators of the benefits and risks associated with treatment. Such information may eventually help to identify stages of disease progression and may be used to guide clinical practice and inform the measurement of outcomes in therapeutic research. Given that patient-reported results were largely missing, in order to gather information regarding the impact of the disease on patients' HRQoL, observer-rated or non-systematic reports on patients' symptoms, functioning and concerns were used as an initial surrogate.

From the early stages of the pandemic, it was recognized that the clinical manifestation of COVD-19 varies considerably and the effect of disease and treatment on patients' HRQoL in the short and long term is still not fully understood. Older adults and individuals with underlying conditions such as diabetes, obesity, and heart and lung disease have been shown to be particularly at risk for developing severe forms of illness [6] and disease progression occurs significantly more rapidly in elderly people compared to the younger population [7]. Symptomatology may evolve considerably during the acute and sub-acute phases of disease, with some symptoms emerging only weeks after the diagnosis [8]. The most severe cases of COVID-19 are prone to a variety of complications, including acute respiratory distress syndrome (ARDS), secondary infections, and acute heart injury [9]. The highly contagious nature of the disease makes the experience of COVID-19 particularly isolating for patients, many of whom must remain in strict confinement at home or in clinics, with little to no direct contact with loved ones and often limited support. This added psychosocial burden may exacerbate an already difficult situation [10]. Patients with confirmed COVID-19 may experience anxiety and fear concerning the high risk for contagion [11] along with guilt and depression in cases of known transmission. In addition to the broader psychosocial implications of a COVID-19 diagnosis, the experience of the disease and its treatment and symptoms may result in depression, anxiety, impaired memory, insomnia, post-traumatic stress disorder (PTSD), and other serious psychiatric complications [12]. Insight into the symptoms and issues that patients who have been diagnosed with COVID-19 face, along with their potential impact on functioning and patients' HRQoL, is an important step in understanding the clinical manifestations 
and their relationship to underlying biological mechanisms and disease prognosis.

With this project, the authors aimed to identify the HRQoL issues relevant for patients with COVID-19, and to use the results as a starting point for the development of a disease-specific patient-reported outcome measure (PROM) for future studies in this patient group. This comprehensive systematic review was carried out to obtain broad coverage of all possible issues to determine the range and prevalence of HRQoL issues affecting COVID-19 patients, relating to their disease and treatment. We explored issues reported by patients, as well as those observed by healthcare providers and other proxy-reporters for patients with COVID-19 during short- and long-term follow-up.

\section{Methods}

The review question was to understand what symptoms and other HRQoL issues are reported by patients with COVID19. The Cochrane guidelines for Systematic Reviews [13] and PRISMA guidelines were followed (see online Appendix 1, for the PRISMA checklist) [14]. The review was registered in PROSPERO (ID =CRD42020185995) [15]. This review differs from a standard systematic review as all report types were included, irrespective of quality, to ensure the broadest coverage possible of COVID-19 patients' symptoms, functioning and concerns.

\section{Search strategy and selection criteria}

A literature search was performed using a combination of controlled vocabulary (e.g. MeSH, EmTree-terms) and freetext search terms for COVID-19, coronavirus disease and related symptoms and concerns, quality of life and patientreported outcomes. The searches were conducted in Embase, MEDLINE, PsycInfo and CINAHL on April 28th 2020. No filters for study design were applied. Only articles published in English, between January 2019 and April 2020 were included. The PRISMA flow diagram (Fig. 1) was used to present the different stages of the review process [16]. The complete search strategy is presented in online Appendix 2.

All references were screened by title and abstract if available. The inclusion criteria were: any publication, letter or news reports which included reports by patients, health care professionals or other proxy-reports of COVID-19 patients' symptoms and other experienced HRQoL issues related to their disease and treatment, at diagnosis, during active disease and during late or long-term follow-up. Exclusion criteria were publications written in a language other than English, or limited to children under the age of 18 years, or publications limited to the societal impact of COVID19 , biological aspects of the virus, or papers specifically related to intensive care unit (ICU) treatment, experiences related to the effect of the pandemic on other diseases, or the emotional reactions of the professionals treating COVID-19 patients.

\section{Screening and full-text review}

Before starting, a session to ensure consistency in the screening process was held. Rayyan QCRI® [17], a web application, was used to facilitate the screening publications. Reviewers were divided into four interdisciplinary, multicultural groups with three reviewers, including at least one clinician, in each group. Each reviewer participated in two pairings within their group and if needed acted as a consultant to the third pairing in the group. Both reviewers within each pair independently screened abstracts and resolved intra-pair disagreements through discussion or through consultation with the third reviewer in the group if consensus could not be reached. A similar process was used for the full-text papers of included abstracts: they were independently checked for eligibility by two reviewers who also extracted data using a checklist of 93 criteria (see below). Any disagreements were resolved through discussion and consultation with the third reviewer if necessary.

\section{Data extraction and categorization}

The initial data extraction sheet aimed to include essential publication characteristics and to pre-specify as many symptoms and HRQoL issues as possible to facilitate data extraction. A review of randomly selected publications was performed until no new issues were retrieved (issue saturation, after 52 publications). The data extraction sheet was pilot-tested by all reviewers on ten randomly selected included studies. This resulted in 93 criteria, classified into four broad categories: (1) inclusion/exclusion criteria, (2) general information on the paper and patient characteristics, (3) reported COVID-19 patient issues, and (4) use of validated PRO questionnaires (online Appendix 3).

Papers were categorised according to study design: reviews, randomised clinical trials, observational studies with $>5$ patients and case studies with $\leq 5$. Reported issues were grouped into categories based on "descriptive themes" that capture HRQoL issues. Categorizing the codes based on descriptive themes was done through a consensus discussion within the project team. The stage of disease at the time the issue reportedly started was categorized as 1: before, at or shortly after diagnosis, 2 : additional symptoms starting after hospitalization or during active disease, and 3: late or longterm (defined as starting after the isolation period ended). Data were analysed using a narrative synthesis. Patient experience and perspective about their HRQoL issues were extracted. 


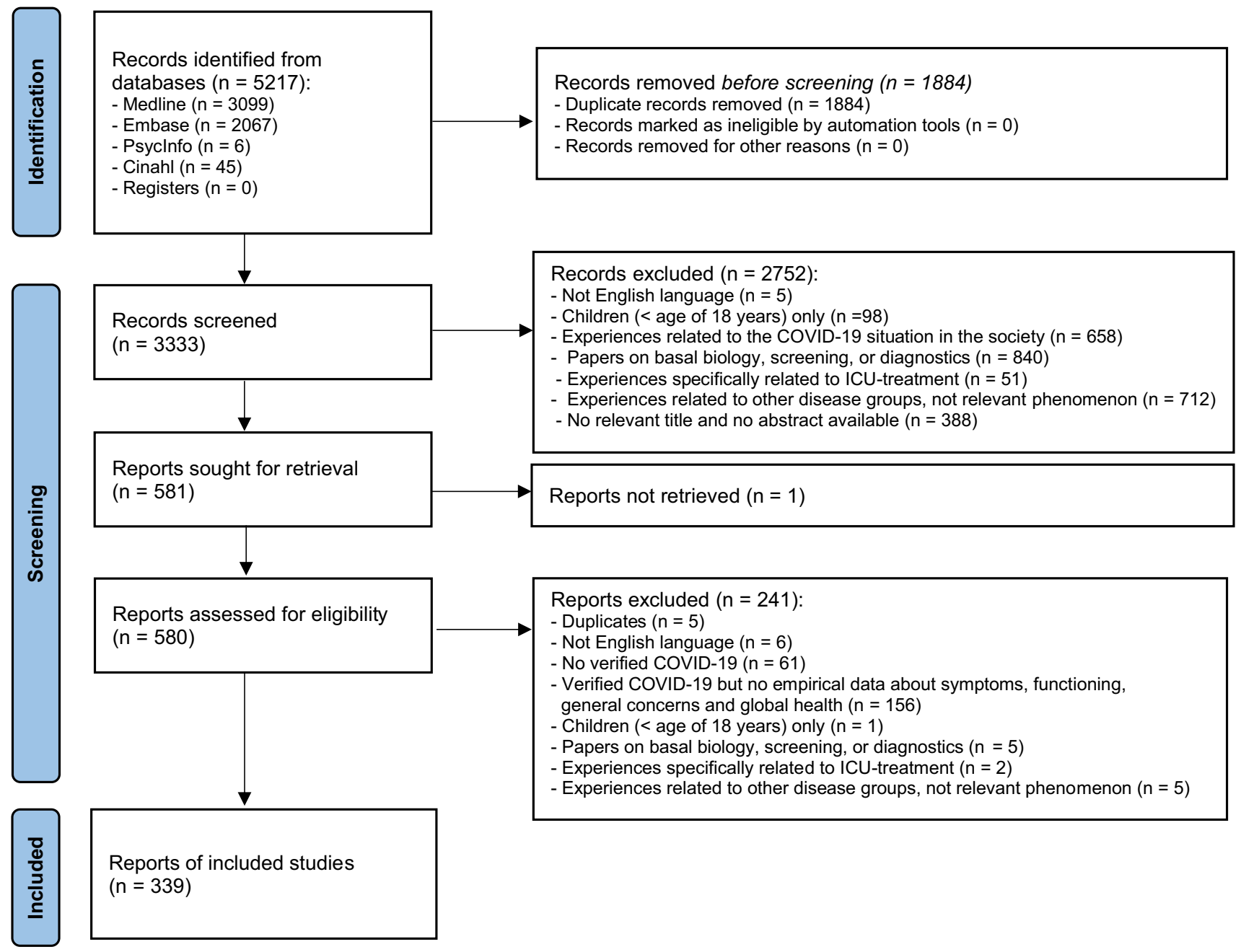

Fig. 1 PRISMA Flow chart of eligibility screening and inclusion

\section{Statistical analyses}

Descriptive statistics are presented using absolute numbers and percentages, and stratified by study type. The descriptions of symptoms, concerns, and functioning were based on observational studies only. Review papers were excluded in the descriptive statistics to avoid double counting of issues. Issues were included if reported in more than one paper or in one paper with more than 10 patients. Comparison of the presence of issues in males and females, and in young ( $<41$ years) and elderly ( $>70$ years) patients was given as an absolute difference in proportions. Graphically, the cumulative proportion by time of publication was presented for selected issues to illustrate different trends in reporting of symptoms during the first four months after the first publication on 24th January 2020.

\section{Updated literature searches}

Updated simplified literature searches were performed on 29th October 2020 and 2nd February 2021, due to the time lag from the original literature search and the large amount of literature produced for this disease. The searches were performed in MEDLINE (search strategies, online Appendix 4). The first author screened references using the same inclusion and exclusion criteria as described for the main search. Fulltext papers were reviewed for issues not already identified, reports on long-term effects after COVID-19, and also for the inclusion of PROMs. 


\section{Results}

The titles and abstracts of 3333 publications were screened and reasons for ineligibility were documented for each of the 2752 papers not selected for full-text review (Fig. 1). We were unable to retrieve a single-page publication published in a magazine with unknown author. Of the 580 papers eligible for full-text review, a total of 339 papers were included (online Appendix 5, details included studies), and the reasons for exclusion of the other 241 papers are displayed in Fig. 1 and online Appendix 6. The main reasons for exclusions were "no empirical data about symptoms, functioning and concerns" and "no verified COVID-19 infection".

\section{Description of included papers and patients}

China was the first country to publish symptom reports after the outbreak of the pandemic and continued to be the dominant publication country, accounting for more than half of the 339 included papers throughout this first period from January to end of April 2020 (Table 1, Fig. 2).

The first reports from other countries started a few weeks later with an increase in publication rate from the end of March 2020. Most studies, independent of origin were observational studies (Table 1). No randomized trials were identified. Nine publications included PROMs. In one study, the psychological impact was assessed with the Impact of Events Scale-Revised (IES-R) [18]. Taste and smell disturbances were assessed in four studies; one used the "Olfactory disorders, Short version of questionnaire of olfactory disorders negative statements of patient" [19], whilst the other three used unnamed ad hoc questionnaires. Four additional studies used unnamed ad hoc questionnaires for patient-reported general symptom assessment.

The number of patients ranged from one to more than fifty thousand per study (Table 1). Most reports included both male and females and all age groups above 18 years old were represented (Table 2). The comorbidity of the patients was either not present or not described in $37 \%$ of the publications. When comorbidities were described, hypertension, diabetes, and cardiovascular and pulmonary disease were most frequently reported (Table 2). Most patients were hospitalized, but several papers described symptoms and concerns of patients in nursing or isolation units or patients who were isolated within their own home.

\section{Symptoms, concerns, and functions reported}

In total, 95 different symptoms, concerns, and functions were described, of which 75 issues were reported in more than one paper or in one paper with more than 10 patients (Table 3). Amongst the observational studies, a median of seven issues (range 1-26) per publication was reported. The number of symptoms reported per paper was stable (median varied between 6 and 10) from January to end of April 2020,

Table 1 Description of papers included stratified by type of study, $n=339$

\begin{tabular}{|c|c|c|c|c|c|c|c|c|c|}
\hline & & \multicolumn{2}{|l|}{$\begin{array}{l}\text { All } \\
n=339\end{array}$} & \multicolumn{2}{|c|}{$\begin{array}{l}\text { Reviews } \\
n=34\end{array}$} & \multicolumn{2}{|c|}{$\begin{array}{l}\text { Observational studies } \\
(>5 \text { patients }) \\
n=159\end{array}$} & \multicolumn{2}{|c|}{$\begin{array}{l}\text { Case studies } \\
(\leq 5 \text { patients }) \\
n=146\end{array}$} \\
\hline & & $n$ & $\%$ & $n$ & $\%$ & $n$ & $\%$ & $n$ & $\%$ \\
\hline \multirow[t]{7}{*}{ Country } & China & 179 & 53 & 16 & 47 & 111 & 70 & 52 & 36 \\
\hline & Asia other & 43 & 13 & 0 & 0 & 10 & 6 & 33 & 23 \\
\hline & Italy/Spain & 25 & 7 & 1 & 3 & 7 & 4 & 17 & 12 \\
\hline & Europe other & 31 & 9 & 1 & 3 & 8 & 5 & 22 & 15 \\
\hline & USA & 30 & 9 & 0 & 0 & 13 & 8 & 17 & 12 \\
\hline & $\begin{array}{l}\text { Other non-European (including Aus- } \\
\text { tralia, Africa and South America) }\end{array}$ & 13 & 4 & 1 & 3 & 7 & 4 & 5 & 3 \\
\hline & Multiple countries & 18 & 5 & 15 & 44 & 3 & 2 & 0 & 0 \\
\hline \multirow[t]{3}{*}{ Type of report } & PROMs included ${ }^{\mathrm{a}}$ & 9 & 3 & 0 & 0 & 8 & 5 & 1 & 1 \\
\hline & PROMs not included & 316 & 93 & 29 & 85 & 148 & 93 & 139 & 95 \\
\hline & Unknown & 14 & 4 & 5 & 15 & 3 & 2 & 6 & 4 \\
\hline \multirow[t]{2}{*}{ Sample size } & Number of patients; median/range & $12 / 1-58,663$ & & & 663 & $73 / 6-9282$ & & $1 / 1-5$ & \\
\hline & Not reported & 7 & 2 & 7 & 21 & 0 & 0 & 0 & 0 \\
\hline
\end{tabular}

Numbers are frequencies and proportions if not otherwise specified

PROMs patient-reported outcome measures

${ }^{a}$ One psychological questionnaire, four related to taste and smell, and four of general symptom assessment 


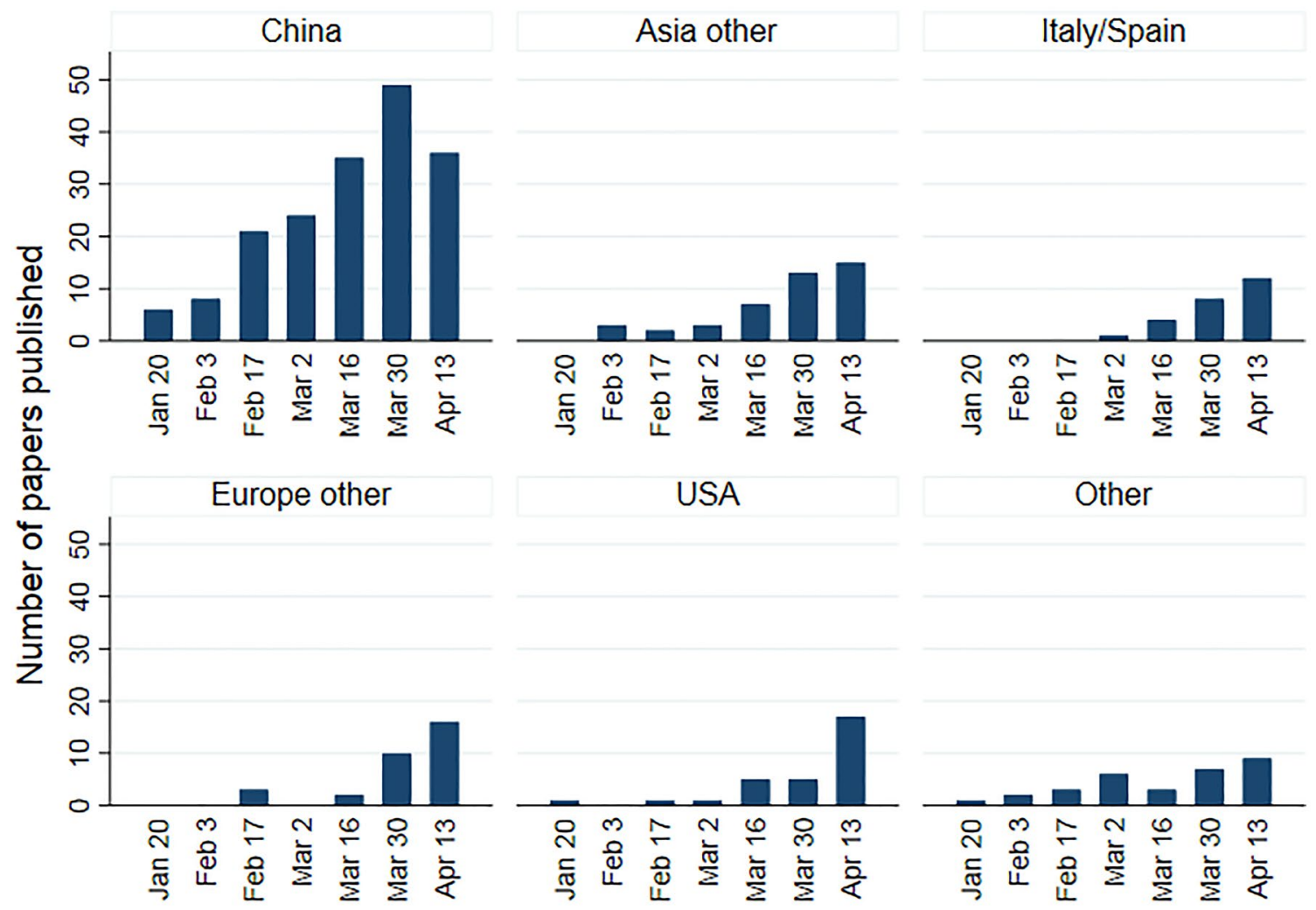

Fig. 2 Number of published papers according to date of publication and geographical origin. Other: non-European countries and multiple countries

but some observational studies reported a higher number of issues at the end of the period compared to studies in the beginning of the period (Fig. 3).

From the start of the pandemic, general symptoms were reported: fever in $90 \%$ and fatigue in $50 \%$ of the publications (Table 3, Fig. 4a). Symptomatic patients commonly presented with cough, shortness of breath, myalgia, headache, and diarrhoea although the range and severity of symptoms differed considerably $[8,20]$. Reports on patients experiencing loss of smell, chest pain, and skin problems came later with an increase from mid-March 2020 (Fig. 4b). All issues were reported to start near the time of diagnosis, and 33 also appeared later during active disease. Very few studies looked at the psychological aspects of the disease (Table 3, Fig. 4c). Some case reports described patients that reported concerns such as fear of being discriminated against in society and the fear of future outcomes [21, 22]. Only one study reported how symptoms affected patients' ability to carry out social activities and influenced their HRQoL [19].

Most studies included patients of all age groups, 48 observational studies included only young patients (age 18-40 years) whilst 19 studies included only the elderly (age $>70$ years) (Table 4). In the descriptive analyses, young patients reported more fatigue, cough, upper respiratory symptoms, myalgia, skin problems and chest problems than the elderly patients (Table 4). In contrast to younger patients, the elderly patients had more problems with level of consciousness, including drowsiness and confusion, and psychological issues such as anxiety and problems with isolation. There were also some differences in symptom manifestation between males and females in the descriptive comparison of studies on gender-specific studies (Table 5). Males experienced fever more frequently, whilst females more often had sore throat, muscle pain and diarrhoea.

\section{Results of the updated literature search}

In the updated search in October 2020 and February 2021, 74 of the 477 identified references met the inclusion criteria. Forty-five were observational studies, of which many included information on patients experiences of psychological symptoms $(n=30)$ and neurological symptoms $(n=15)$.

Sixteen studies provided results on long COVID, including persistent or late effects after discharge or during followup (online Appendix 7). The presence of different symptoms at different time points or over a certain time-period was reported, not the duration of each symptom. Across different continents, $28-74 \%$ of the patients had persistent respiratory 
Table 2 Description of patients included in the 339 papers stratified by type of study

\begin{tabular}{|c|c|c|c|c|c|c|c|c|c|}
\hline & & $\begin{array}{l}\text { All papers } \\
n=339\end{array}$ & & $\begin{array}{l}\text { Review } \\
n=34\end{array}$ & & $\begin{array}{l}\text { Observational } \\
\text { studies } \\
\text { (>5 patients) } \\
n=159\end{array}$ & & $\begin{array}{l}\text { Case studi } \\
(\leq 5 \text { patier } \\
n=146\end{array}$ & \\
\hline & & $n$ & $\%$ & $n$ & $\%$ & $n$ & $\%$ & $n$ & $\%$ \\
\hline \multirow[t]{4}{*}{ Gender } & Male & 65 & 19 & 0 & 0 & 1 & 0.6 & 64 & 44 \\
\hline & Female & 51 & 15 & 1 & 3 & 6 & 4 & 44 & 30 \\
\hline & Both & 204 & 60 & 25 & 74 & 145 & 91 & 34 & 23 \\
\hline & Unknown & 19 & 6 & 8 & 24 & 7 & 4 & 4 & 3 \\
\hline \multirow[t]{5}{*}{ Age Specified } & Yes, young 18-40 & 211 & 67 & 16 & 67 & 131 & 86 & 63 & 45 \\
\hline & Yes, middle-aged 41-70 & 242 & 76 & 18 & 75 & 143 & 94 & 80 & 57 \\
\hline & Yes, elderly/old > 70 & 138 & 44 & 14 & 58 & 96 & 63 & 27 & 19 \\
\hline & Not specified & 23 & 7 & 10 & 29 & 7 & 4 & 6 & 4 \\
\hline & Reported median (years)/range & $49 / 22-86.5$ & & $50 / 41-70$ & & $48.8 / 22-86.5$ & & $49 / 22-81$ & \\
\hline \multirow[t]{16}{*}{ Comorbidity } & Hypertension & 139 & 41 & 15 & 44 & 91 & 57 & 33 & 23 \\
\hline & Diabetes & 131 & 39 & 17 & 50 & 91 & 57 & 23 & 16 \\
\hline & Cardiovascular disease & 110 & 32 & 12 & 35 & 80 & 50 & 18 & 12 \\
\hline & Pulmonary disease & 104 & 31 & 11 & 32 & 85 & 53 & 8 & 5 \\
\hline & Cancer & 67 & 20 & 7 & 21 & 52 & 33 & 8 & 5 \\
\hline & Kidney/urinary system disease & 66 & 19 & 4 & 12 & 47 & 30 & 15 & 10 \\
\hline & Liver disease & 61 & 18 & 7 & 21 & 47 & 30 & 7 & 5 \\
\hline & Cerebrovascular disease & 33 & 10 & 1 & 3 & 31 & 20 & 1 & 0.7 \\
\hline & Autoimmune disease and immunodeficiency & 33 & 10 & 1 & 3 & 20 & 13 & 12 & 8 \\
\hline & Endocrine disease/disorder & 25 & 7 & 1 & 3 & 20 & 13 & 4 & 3 \\
\hline & Gastrointestinal disease/disorder & 20 & 6 & 1 & 3 & 18 & 11 & 1 & 0.7 \\
\hline & Neurological disease & 16 & 5 & 2 & 6 & 12 & 8 & 2 & 1 \\
\hline & Infectious disease & 15 & 4 & 1 & 3 & 12 & 8 & 2 & 1 \\
\hline & Psychiatric disease & 6 & 2 & 0 & 0 & 4 & 3 & 2 & 1 \\
\hline & Other specified & 39 & 12 & 3 & 9 & 20 & 13 & 16 & 11 \\
\hline & No/not described & 124 & 37 & 15 & 44 & 46 & 29 & 63 & 43 \\
\hline \multirow[t]{4}{*}{ Hospitalisation } & Intensive care unit (ICU) & 100 & 29 & 15 & 44 & 59 & 37 & 26 & 18 \\
\hline & Hospital, not ICU & 266 & 78 & 19 & 56 & 133 & 84 & 114 & 78 \\
\hline & Nursing home or isolation units or own home & 49 & 14 & 3 & 9 & 23 & 14 & 23 & 16 \\
\hline & No/not described & 45 & 13 & 15 & 44 & 17 & 11 & 13 & 9 \\
\hline
\end{tabular}

Numbers are frequencies and proportions if not otherwise specified

symptoms and $28-72 \%$ had fatigue $1-4$ months after discharge $[23,24]$, and this seemed to be independent of the severity of the COVID-19 infection [25]. Reduced physical and mental health were also observed in patients several weeks after discharge for severe COVID-19 [26]. Anxiety, depression, and cognitive deficits (affected short-term memory, attention and concentration) [24, 27, 28], pain, discomfort, sleep disturbances and headache were reported more than 4 weeks after discharge [27, 29]. In a longitudinal study, 538 survivors reported a large range of persistent symptoms 3 months after discharge (general, respiratory, cardiovascular and psychosocial) of which the most common were fatigue and hair loss [30]. The large symptom burden and reduced levels of functioning mean that many patients with COVID-19 experience reduced HRQoL for several months after infection [23, 31, 32]. Three new symptoms not included in Table 3 were identified: change of voice $(n=1)$ [32], dysphagia $(n=2)[32,33]$ and suicidal thoughts $(n=1)$ [34]. In addition, one paper reported optimism, hope, resilience, and self-efficacy in nurses returning to work after recovering from the infection [35]. Also, PTSD and complications such as stroke and encephalopathy were described following COVID-19 in patients [34, 36, 37].

The updated search identified 24 publications that included PROMs. Most measures were symptom-specific $(n=20)$ measuring fatigue [25], respiratory symptoms [23] and mental health [37] and four studies used generic questionnaires: SF-36 [31, 38], EQ-5D [32] or Patient Health 
Table 3 Description of symptoms, reduced functions and concerns from observational studies, 305 papers

\begin{tabular}{|c|c|c|c|}
\hline Issue $^{\mathrm{a}}$ & Number of papers $(\%)$ & $\begin{array}{l}\text { Start of symptom early/ } \\
\text { active }^{b}\end{array}$ & Descriptive themes \\
\hline Fever & $273(90)$ & $262 / 11$ & General symptoms \\
\hline Chills or shivering & $53(17)$ & $50 / 3$ & \\
\hline Fatigue or asthenia including weakness & $153(50)$ & $150 / 3$ & \\
\hline Malaise/feeling sick & $25(8)$ & $25 / 0$ & \\
\hline Extensive sweating or night sweats & $4(1)$ & $4 / 0$ & \\
\hline Dizziness & $32(10)$ & $31 / 1$ & \\
\hline Drowsiness & $5(2)$ & $4 / 1$ & Level of consciousness \\
\hline Confusion or delirium & $20(7)$ & $17 / 3$ & \\
\hline Unconscious & $3(1)$ & $3 / 0$ & \\
\hline Cough & $249(82)$ & $236 / 13$ & Respiration \\
\hline Shortness of breath, dyspnoea or respiratory distress & $196(64)$ & $178 / 18$ & \\
\hline Expectoration lung & $82(27)$ & $80 / 2$ & \\
\hline Haemoptysis/blood in the expectoration & $25(8)$ & $24 / 1$ & \\
\hline Oral (mouth) mucus or saliva & $13(4)$ & $13 / 0$ & Mouth/throat \\
\hline Pharyngodynia/sore throat & $113(37)$ & $110 / 3$ & \\
\hline Throat congestion & $2(0,7)$ & $2 / 0$ & \\
\hline Tonsil swelling & $1(0,3)$ & $1 / 0$ & \\
\hline Sneezing & $8(3)$ & $8 / 0$ & Nose \\
\hline Mucus in the nose or nasal congestion & $35(11)$ & $33 / 2$ & \\
\hline Rhinorrhoea/coryza/runny nose & $63(21)$ & $58 / 5$ & \\
\hline Nasal symptoms & $1(0.3)$ & $1 / 0$ & \\
\hline Epistaxis/nose bleeding & $2(0.7)$ & $2 / 0$ & \\
\hline Otalgia/ear pain & $4(1)$ & $4 / 0$ & Ear \\
\hline Hearing loss & $2(0.7)$ & $2 / 0$ & \\
\hline Tinnitus & $3(1)$ & $3 / 0$ & \\
\hline Irritation eyes or sore eyes & $9(3)$ & $8 / 1$ & Eye \\
\hline Red eyes & $6(2)$ & $6 / 0$ & \\
\hline General pain & $12(4)$ & $10 / 2$ & Pain \\
\hline Myalgia/general muscle pain & $135(44)$ & $132 / 3$ & \\
\hline Neuropathic/neurological pain & $1(0,3)$ & $1 / 0$ & \\
\hline Headache & $116(38)$ & $115 / 1$ & \\
\hline Muscle soreness & $1(0.3)$ & $2 / 0$ & \\
\hline Arthralgia/ joint pain & $15(5)$ & $15 / 0$ & \\
\hline Back pain & $3(1)$ & $3 / 0$ & \\
\hline Facial pain or heaviness & $1(0.3)$ & $1 / 0$ & \\
\hline Loss of taste & $21(7)$ & $20 / 1$ & Neuropathic-neurological \\
\hline Loss of smell & $23(8)$ & $21 / 2$ & \\
\hline Sight problems or vision & $2(0.7)$ & $2 / 0$ & \\
\hline Uncoordinated movements & $1(0.3)$ & $1 / 0$ & \\
\hline Seizure & $4(1)$ & $3 / 1$ & \\
\hline
\end{tabular}


Table 3 (continued)

\begin{tabular}{|c|c|c|c|}
\hline Issue $^{a}$ & Number of papers $(\%)$ & $\begin{array}{l}\text { Start of symptom early/ } \\
\text { active }^{\text {b }}\end{array}$ & Descriptive themes \\
\hline Diarrhoea & $152(50)$ & $140 / 12$ & Gastrointestinal \\
\hline Constipation & $7(2)$ & $6 / 1$ & \\
\hline Nausea & $73(24)$ & $70 / 3$ & \\
\hline Vomiting & $74(24)$ & $71 / 3$ & \\
\hline Anorexia/loss of appetite & $43(14)$ & $43 / 0$ & \\
\hline Stomach ache/abdominal pain & $50(16)$ & $47 / 3$ & \\
\hline Belching & $2(0.7)$ & $2 / 0$ & \\
\hline Acid reflux & $1(0.3)$ & $1 / 0$ & \\
\hline Abdominal distention & $1(0.3)$ & $1 / 0$ & \\
\hline Bloating & $2(0.7)$ & $2 / 0$ & \\
\hline Tenesmus/bowel cramps & $1(0.3)$ & $1 / 0$ & \\
\hline Gastrointestinal discomfort & $1(0.3)$ & $1 / 0$ & \\
\hline Gastrointestinal symptoms & $6(2)$ & $6 / 0$ & \\
\hline Dysuria & $1(0.3)$ & $1 / 0$ & Urinary \\
\hline Haematuria/blood in urine & $2(0.7)$ & $2 / 0$ & \\
\hline Rash including urticaria & $18(6)$ & $14 / 4$ & Skin \\
\hline Pruritus/itching & $6(2)$ & $5 / 1$ & \\
\hline Skin pain or burning sensation & $3(1)$ & $3 / 0$ & \\
\hline Hair loss & $1(0.3)$ & $1 / 0$ & \\
\hline Chest pain & $48(16)$ & $44 / 4$ & Chest-cardio \\
\hline Tightness of chest & $34(11)$ & $32 / 2$ & \\
\hline Chest distress & $13(4)$ & $12 / 1$ & \\
\hline Heart palpitations & $8(3)$ & $7 / 1$ & \\
\hline Anxiety & $9(3)$ & $6 / 3$ & Psychological-psychiatric \\
\hline Depression & $3(1)$ & $2 / 1$ & \\
\hline Distress & $2(0.7)$ & $1 / 1$ & \\
\hline Tension & $1(0.3)$ & $1 / 0$ & \\
\hline Agitation & $3(1)$ & $2 / 1$ & \\
\hline Anger & $2(0.7)$ & $2 / 0$ & \\
\hline Insomnia & $2(0.7)$ & $2 / 0$ & \\
\hline Fear of being discriminated against society & $2(0.7)$ & $2 / 0$ & Concern \\
\hline Fear of future outcome & $2(0.7)$ & $2 / 0$ & \\
\hline Fear of cold & $1(0.3)$ & $1 / 0$ & \\
\hline Activity daily living & $2(0.7)$ & $2 / 0$ & Functions \\
\hline Social activities & $1(0.3)$ & $1 / 0$ & \\
\hline
\end{tabular}

No papers reported additional symptoms specifically appearing at long-term follow-up

${ }^{\mathrm{a}}$ Issues are included if reported in more than one paper or in one paper with more than 10 patients

bThe stage of disease during which a symptom or issue were reported to appear was categorized as "early" (before, at or shortly after diagnosis) or "active" (additional symptoms starting after hospitalization or during active disease)

Questionnaire [23]. Twelve studies included more than two questionnaires. None of these questionnaires had been validated for use in patients with COVID-19.

\section{Discussion}

This systematic literature review was performed with the aim of gathering as much information relevant to the HRQoL of patients with COVID-19 as possible. We therefore included 
Fig. 3 Number of issues reported per paper according to date of publication for observational studies. Lines are local weighted average smoother with bandwidth 0.8

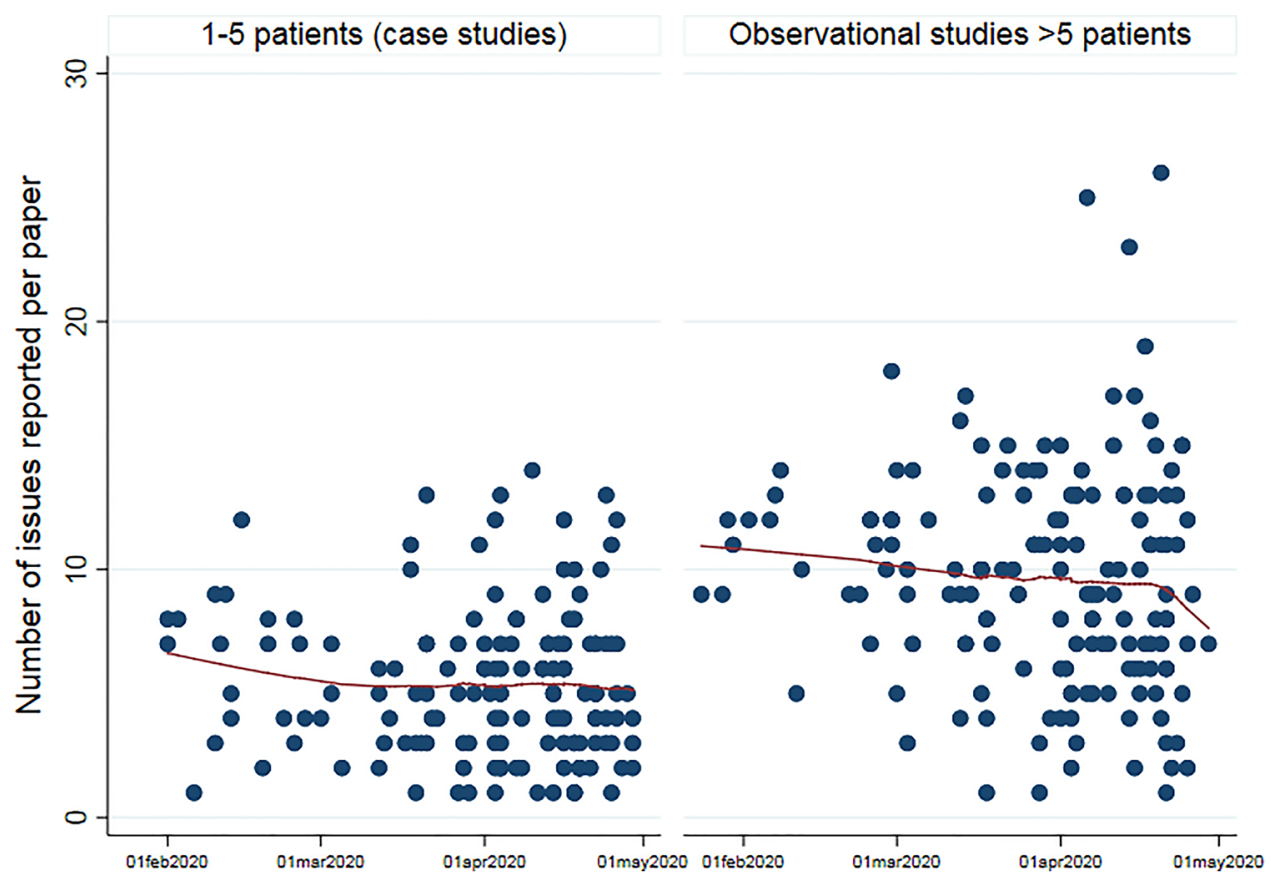

all types of publications, study designs and research settings. The updated searches, performed 6 and 9 months later, identified virtually no new symptoms or concerns. This confirms that our review has succeeded in obtaining a comprehensive overview of HRQoL issues experienced by patients with current or previous symptomatic disease, and for the followup period. The content validity of the identified issues is therefore supported. Our review did not identify any PROM developed specifically for these patients, supporting the need for an internationally developed HRQoL instrument for patients during and after COVID-19. The multiplicity of devastating symptoms and functional deficit related to this disease, both in the acute phase and long-term follow-up may have large implications for the patients themselves and their families. COVID-19 affects people of all ages, and the symptom burden may also give reduced working abilities and societal challenges.

Despite COVID-19 being a novel disease, in this review, there was very good representation of patients from different care-settings and age groups, with several different comorbidities. The reports included both females and males, with the exception of some case reports and a few studies on gender-specific populations such as patients in a maternity ward [39]. Reports from China, the first country to publish descriptions on COVID-19-specific symptoms, focused on core symptoms such as fever, cough, shortness of breath and diarrhoea and a large proportion of patients across all ages needed hospital admission and intensive care. With time, as the disease spread and new phases of the disease trajectory were experienced, additional issues such as alteration of senses (taste, smell) [19] and cutaneous manifestations [40], began to appear as the complexity of the disease gradually came to light. This review includes studies from all continents; thereby reflecting cross-cultural HRQoL issues.

The large variation in type and severity of acute symptoms highlight the need for clinicians to have a high level of vigilance and initiate necessary measures when COVID19 is suspected. For patients with confirmed diagnosis, all symptoms experienced and their influence on HRQoL need to be mapped, during active disease and in the follow-up period, in order to initiate adequate treatment and care. The COVID-19 HRQoL questionnaire developed in this project would be well suited for this purpose. The large variation in HRQoL issues that patients with COVID-19 experience during the infection and recovery period also highlights the need for cooperation between different levels of the health care services to ensure optimal care for patients along with the best possible use of resources.

The initial lack of psychological symptoms and concerns reported might have been caused by investigators who were focused on describing symptoms that could help identify and control the spread of the disease. At this stage, psychological symptoms, patient functioning, and concerns and how these issues impacted patients' HRQoL might have been regarded as less important. The updated search revealed that more recent publications have had an increased focus on the psychological impact of the disease both during [41] and after discharge from hospital [24, 27, 42]. Patients in rehabilitation with post-acute COVID-19 had ongoing physical and psychological symptoms and reduced HRQoL [30, 32, 43]. Experiences from follow-up studies show that some patients with COVID-19 also experience fatigue, anxiety, depression, 
a

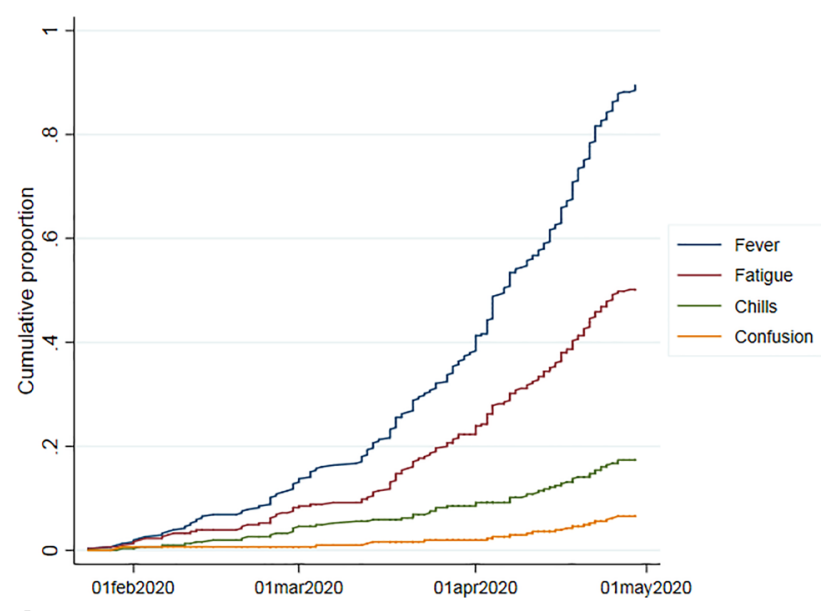

b

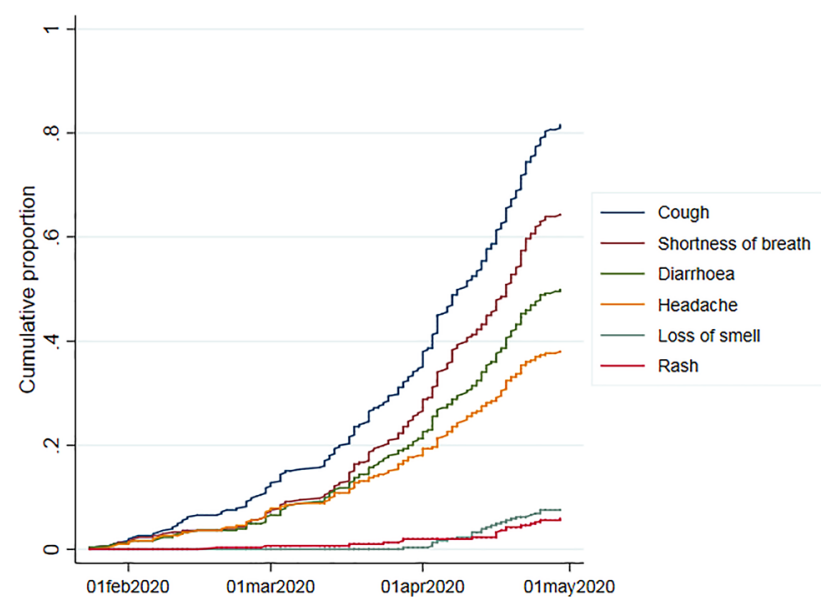

C

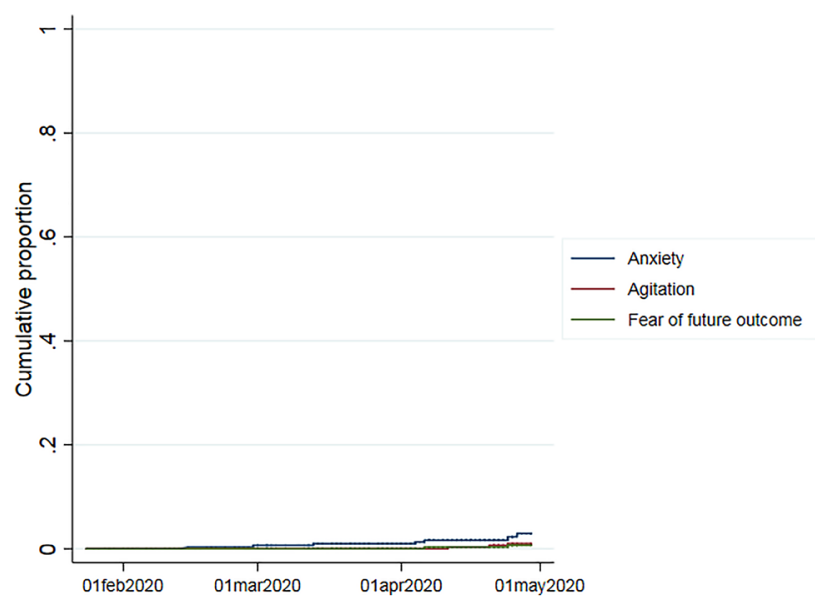

Fig. 4 Cumulative proportion of papers over time reporting selected a general symptoms, $\mathbf{b}$ other symptoms and $\mathbf{c}$ psychological symptoms and concerns

PTSD and impaired cognitive function in the long term [12, 28, 30, 44]. Most symptoms reported in the months after discharge seemed to be a continuation of symptoms experienced during active disease, but new symptoms were also described such as problems with attention, concentration, obsessive-compulsive symptoms and PTSD. This finding emphasises that COVID-19 entails a large variation in disease trajectories. Health care providers need to be aware of these differences in disease courses to be able to provide adequate care for patients during the acute phase of the disease and also during follow-up after COVID-19 infection.

Young patients reported more symptoms than elderly patients. This was contradictory to what we expected as elderly patients are at risk for developing more severe disease with rapid progression [6, 7]. A possible explanation is that elderly patients seeking medical care for other conditions were more often tested whereas young patients were only tested if they had the core symptoms. It was also interesting that elderly patients had more emotional symptoms than the young, counter to the usual finding that elderly people are less emotionally disturbed by illness [45]. Increased social isolation may have had more of an impact on older people, particularly because of the publicity around elderly people being at an increased risk of developing severe COVID-19. The possible differences in the acute symptom manifestation for males and females described in this review needs to be confirmed in other studies. Knowing more about gender differences would help clinicians better understand the disease. One study reported that males seemed to have a higher risk of getting severely ill than females and were more often in need of intensive care [46].

\section{Use of PROMs}

Even though this disease carries a heavy symptom burden, the use of PROM remains rare. This may be partly explained by the lack of a COVID-19-specific PROM. Contrary to our expectations, only a few studies used generic questionnaires [31, 32, 38, 47]. Halpin et al., reported reduced HRQoL measured with the EQ-5D in more than 50\% (53/100) of patients discharged from hospital after treatment for COVID-19 [32]. The problem with using generic questionnaires to assess HRQoL is their low sensitivity to change, along with the potential for weak content validity and missed symptoms. Therefore, it is often recommended to combine generic and disease-specific questionnaires [48]. Some studies used non-validated questionnaires [49, 50], which should be strongly discouraged as it entails a high risk for unreliable results.

This systematic literature review represents the first important step in the development of an international COVID-19-specific questionnaire, insofar as the results point to issues that should be included in the measure. Without such a questionnaire there is a significant risk that researchers might put together instruments that are incomplete and not validated for these patients. This can produce 
Table 4 Themes and Issues by Age from observational studies, 305 papers

\begin{tabular}{|c|c|c|c|c|c|}
\hline \multirow[t]{2}{*}{ Themes and Issues } & Young (48 papers) & $\begin{array}{l}\text { Middle- } \\
\text { aged ( } 65 \\
\text { papers) }\end{array}$ & Elderly (19 papers) & Mixed (160 papers) & Young vs. elderly \\
\hline & $n(\%)$ & $n(\%)$ & $n(\%)$ & $n(\%)$ & Difference in proportions \\
\hline General & $43(90)$ & $58(89)$ & $17(89)$ & $158(99)$ & 1 \\
\hline Fever & $39(81)$ & $58(89)$ & $14(74)$ & $157(98)$ & 7 \\
\hline $\begin{array}{l}\text { Fatigue or asthenia including weak- } \\
\text { ness }\end{array}$ & $18(38)$ & $26(40)$ & $5(26)$ & $103(64)$ & $12^{*}$ \\
\hline Level of consciousness & $2(4)$ & $2(3)$ & $4(21)$ & $14(9)$ & $-17^{*}$ \\
\hline Respiration & $36(75)$ & $60(92)$ & $13(68)$ & $153(96)$ & 7 \\
\hline Cough & $36(75)$ & $48(74)$ & $11(58)$ & $151(94)$ & $17 *$ \\
\hline $\begin{array}{l}\text { Shortness of breath, dyspnoea or } \\
\text { respiratory distress }\end{array}$ & $22(46)$ & $37(57)$ & $8(42)$ & $126(79)$ & 4 \\
\hline Mouth/throat & $12(25)$ & $13(20)$ & $2(11)$ & $93(58)$ & $14^{*}$ \\
\hline Pharyngodynia/sore throat & $12(25)$ & $10(15)$ & $1(5)$ & $89(56)$ & $20^{*}$ \\
\hline Nose & $13(27)$ & $8(12)$ & $0(0)$ & $60(38)$ & $27 *$ \\
\hline Ear/Eye & $4(8)$ & $3(5)$ & $1(5)$ & $7(4)$ & 3 \\
\hline Pain & $18(38)$ & $29(45)$ & $2(11)$ & $124(78)$ & $27^{*}$ \\
\hline Myalgia/general muscle pain & $14(29)$ & $20(31)$ & $1(5)$ & $100(63)$ & $24^{*}$ \\
\hline Headache & $4(8)$ & $15(23)$ & $0(0)$ & $96(60)$ & 8 \\
\hline Neuropathic- neurological & $3(6)$ & $8(12)$ & $2(11)$ & $11(7)$ & -5 \\
\hline Gastrointestinal/Urinary & $23(48)$ & $24(37)$ & $10(53)$ & $125(78)$ & -5 \\
\hline Diarrhoea & $19(40)$ & $17(26)$ & $7(37)$ & $108(68)$ & 3 \\
\hline Skin & $6(13)$ & $1(2)$ & $0(0)$ & $10(6)$ & $13^{*}$ \\
\hline Chest-cardio & $14(29)$ & $12(18)$ & $3(16)$ & $49(31)$ & $13^{*}$ \\
\hline $\begin{array}{l}\text { Psychological-psychiatric/concern/ } \\
\text { functions }\end{array}$ & $3(6)$ & $8(12)$ & $5(26)$ & $20(13)$ & $-20 *$ \\
\hline
\end{tabular}

Age not specified in 13 papers

*Absolute difference (young-elderly) in proportions $>10 \%$ shown in bold values

results that, in the worst case, could lead to misjudged treatment decisions and harm patients.

\section{Strengths and limitations}

The strength of this comprehensive systematic literature review was the application of a robust methodology following international guidelines and the publishing of the protocol upfront in PROSPERO.

By including a variety of studies and publications, including letters and case reports without a systematic quality assessment, studies might have been biased, with nonrepresentative patient populations. On the other hand, our focus was not to retrieve a quantitative assessment of the incidence/prevalence of symptoms, but rather to achieve a broad insight of these issues very early in the pandemic. Only English publications were reviewed, so issues reported in other languages might have been missed. We believe that the risk for this is small given the extensive list of issues identified and the very few additional issues identified in the updated review. Information on HRQoL issues specific to children is not covered in this review, even though some of the publications may include a broad age-range. Late effects more than a year after COVID-19 may be lacking, as the last literature search was performed less than 1.5 years after the start of the pandemic.

\section{Conclusion}

In this comprehensive review we found a wide range of reported HRQoL issues affecting most of the organ systems in patients with COVID-19. The variety of clinical manifestations and their impact on patients' HRQoL, together with the finding that all symptoms were present in the acute phase of the disease, is important information for clinicians to better recognize and understand the disease. This has important clinical implications for diagnosis, treatment Queryand follow-up of patients with COVID-19. For patients with COVID-19 and their next of kin, it can give greater insight into many different clinical aspects of the disease and support self-management. The results provided the foundation 
Table 5 Themes and Issues by gender from observational studies, 305 papers

\begin{tabular}{|c|c|c|c|c|}
\hline \multirow[t]{2}{*}{ Themes and Issues } & \multirow{2}{*}{$\begin{array}{l}\text { Female (50 papers) } \\
n(\%)\end{array}$} & \multirow{2}{*}{$\begin{array}{l}\text { Male (65 papers) } \\
n(\%)\end{array}$} & \multirow{2}{*}{$\begin{array}{l}\text { Both gender } \\
(179 \text { papers }) \\
n(\%)\end{array}$} & \multirow{2}{*}{$\begin{array}{l}\text { Female vs. male } \\
\text { Difference in proportions }\end{array}$} \\
\hline & & & & \\
\hline General & $41(82)$ & $61(94)$ & $176(98)$ & $-12^{*}$ \\
\hline Fever & $38(76)$ & $57(88)$ & $175(98)$ & $-12^{*}$ \\
\hline Fatigue or asthenia including weakness & $17(34)$ & $21(32)$ & $114(64)$ & 2 \\
\hline Level of consciousness & $0(0)$ & $6(9)$ & $16(9)$ & -9 \\
\hline Respiration & $41(82)$ & $53(82)$ & $170(95)$ & 0 \\
\hline Cough & $37(74)$ & $42(65)$ & $168(94)$ & 9 \\
\hline Shortness of breath, dyspnoea or respiratory distress & $22(44)$ & $31(48)$ & $141(79)$ & -4 \\
\hline Mouth/throat & $11(22)$ & $4(6)$ & $105(59)$ & $16^{*}$ \\
\hline Pharyngodynia/sore throat & $10(20)$ & $4(6)$ & $98(55)$ & $14^{*}$ \\
\hline Nose & $5(10)$ & $11(17)$ & $65(36)$ & -7 \\
\hline Ear/Eye & $3(6)$ & $4(6)$ & $9(5)$ & 0 \\
\hline Pain & $21(42)$ & $17(26)$ & $135(75)$ & $16^{*}$ \\
\hline Myalgia/general muscle pain & $17(34)$ & $9(14)$ & $108(60)$ & $20 *$ \\
\hline Headache & $5(10)$ & $8(12)$ & $102(57)$ & -2 \\
\hline Neuropathic- neurological & $5(10)$ & $4(6)$ & $15(8)$ & 4 \\
\hline Gastrointestinal/Urinary & $23(46)$ & $25(38)$ & $133(74)$ & 8 \\
\hline Diarrhoea & $20(40)$ & $16(25)$ & $114(64)$ & $15^{*}$ \\
\hline Skin & $5(10)$ & $2(3)$ & $10(6)$ & 7 \\
\hline Chest—cardio & $12(24)$ & $12(18)$ & $54(30)$ & 6 \\
\hline Psychological-psychiatric/concern/functions & $0(0)$ & $5(8)$ & $10(6)$ & -8 \\
\hline
\end{tabular}

Gender unknown in 11 papers

*Absolute difference (female-male) in proportions $>10 \%$ shown in bold values

for the international development of a COVID-19 specific patient-reported HRQoL questionnaire.

Supplementary Information The online version contains supplementary material available at https://doi.org/10.1007/s11136-021-02908-z.

Acknowledgements We highly appreciate that the affiliated institutions have made it possible for us to do this work without external funding.

Author contributions $\mathrm{CDA}$ and $\mathrm{KB}$ conceived the idea, established the international collaboration and co-ordinated the review. $\mathrm{CDA}, \mathrm{KB}$, $\mathrm{MP}, \mathrm{RSF}, \mathrm{CP}$ and $\mathrm{AB}$ constituted the writing committee. CDA and MP registered the protocol in PROSPERO. RSF and CDA performed the analyses and designed tables and figures. NMHJ was responsible for establishing and performing the systematic literature search. All authors except SAR and NMHJ were involved in both steps of the review; abstracts for inclusion and full-text review of papers for issue extractions. SAR was responsible for the first step of the review in Rayyan and co-ordinated the inputs from all reviewers. The writing committee wrote the first draft of the publication; all authors were involved in editing successive drafts and approved the final submitted version.

Funding Open access funding provided by University of Oslo (incl Oslo University Hospital). None declared.

Data availability Not applicable.
Code availability Not applicable.

\section{Declarations}

Conflict of interest SS received personal fees from Pfizer, BoehringerIngelheim, and Lilly, all outside of the submitted work. No other authors declare competing interests.

Open Access This article is licensed under a Creative Commons Attribution 4.0 International License, which permits use, sharing, adaptation, distribution and reproduction in any medium or format, as long as you give appropriate credit to the original author(s) and the source, provide a link to the Creative Commons licence, and indicate if changes were made. The images or other third party material in this article are included in the article's Creative Commons licence, unless indicated otherwise in a credit line to the material. If material is not included in the article's Creative Commons licence and your intended use is not permitted by statutory regulation or exceeds the permitted use, you will need to obtain permission directly from the copyright holder. To view a copy of this licence, visit http://creativecommons.org/licenses/by/4.0/.

\section{References}

1. Zhu, N., Zhang, D., Wang, W., Li, X., Yang, B., Song, J., Zhao, X., Huang, B., Shi, W., Lu, R., \& Niu, P. (2020). A novel Coronavirus from patients with pneumonia in China, 2019. New England 
Journal of Medicine, 382(8), 727-733. https://doi.org/10.1056/ NEJMoa2001017

2. Bjordal, K., \& Kaasa, S. (1992). Psychometric validation of the EORTC core quality of life questionnaire, 30 -item version and a diagnosis-specific module for head and neck cancer patients. Acta Oncologica, 31(3), 311-321. https://doi.org/10.3109/0284186920 9108178

3. Bjordal, K., de Graeff, A., Fayers, P. M., Hammerlid, E., van Pottelsberghe, C., Curran, D., Ahlner-Elmqvist, M., Maher, E. J., Meyza, J. W., Bredart, A., \& Söderholm, A. L. (2000). A 12 country field study of the EORTC QLQ-C30 (version 3.0) and the head and neck cancer specific module (EORTC QLQ-H\&N35) in head and neck patients. EORTC Quality of Life Group. European Journal of Cancer, 36(14), 1796-1807.

4. Wu, C., Chen, X., Cai, Y., Xia, J., Zhou, X., Xu, S., Huang, H., Zhang, L., Zhou, X., Du, C., Zhang, Y., \& Song, J. (2020). Risk factors associated with acute respiratory distress syndrome and death in patients with Coronavirus disease 2019 pneumonia Wuhan China. JAMA internal medicine. https://doi.org/10.1001/ jamainternmed.2020.0994

5. Yan, C. H., Faraji, F., Prajapati, D. P., Boone, C. E., \& DeConde, A. S. (2020). Association of chemosensory dysfunction and Covid-19 in patients presenting with influenza-like symptoms. International Forum of Allergy \& Rhinology. https://doi.org/10. 1002/alr.22579

6. Williamson, E. J., Walker, A. J., Bhaskaran, K., Bacon, S., Bates, C., Morton, C. E., Curtis, H. J., Mehrkar, A., Evans, D., Inglesby, P., \& Cockburn, J. (2020). Factors associated with COVID-19-related death using OpenSAFELY. Nature, 584(7821), 430-436. https://doi.org/10.1038/ s41586-020-2521-4

7. Wang, W., Tang, J., \& Wei, F. (2020). Updated understanding of the outbreak of 2019 novel coronavirus (2019-nCoV) in Wuhan China. Journal of Medical Virology, 92(4), 441-447. https://doi. org/10.1002/jmv.25689

8. Lescure, F. X., Bouadma, L., Nguyen, D., Parisey, M., Wicky, P. H., Behillil, S., Gaymard, A., Bouscambert-Duchamp, M., Donati, F., Le Hingrat, Q., \& Enouf, V. (2020). Clinical and virological data of the first cases of COVID-19 in Europe: A case series. Lancet Infectious Diseases, 20(6), 697-706. https://doi.org/10. 1016/s1473-3099(20)30200-0

9. Chen, N., Zhou, M., Dong, X., Qu, J., Gong, F., Han, Y., Qiu Y., Wang J., Liu Y., Wei Y., Yu T. (2020). Epidemiological and clinical characteristics of 99 cases of 2019 novel coronavirus pneumonia in Wuhan, China: a descriptive study. Lancet, 395(10223), 507-513. https://doi.org/10.1016/s0140-6736(20)30211-7.

10. Dubey, S., Biswas, P., Ghosh, R., Chatterjee, S., Dubey, M. J., Chatterjee, S., Dubey, M. J., Chatterjee, S., Lahiri, D., \& Lavie, C. J. (2020). Psychosocial impact of COVID-19. Diabetes \& Metabolic Syndrome, 14(5), 779-788. https://doi.org/10.1016/j.dsx. 2020.05.035

11. Wang, C., Pan, R., Wan, X., Tan, Y., Xu, L., Ho, C. S., \& Ho, R. C. (2020). Immediate psychological responses and associated factors during the initial stage of the 2019 Coronavirus disease (COVID-19) epidemic among the general population in China. International Journal of Environmental Research and Public Health. https://doi.org/10.3390/ijerph17051729

12. Rogers, J. P., Chesney, E., Oliver, D., Pollak, T. A., McGuire, P., Fusar-Poli, P., MichaelZandi, S., Lewis, G., \& Anthony David, S. (2020). Psychiatric and neuropsychiatric presentations associated with severe coronavirus infections: A systematic review and meta-analysis with comparison to the COVID-19 pandemic. Lancet Psychiatry, 7(7), 611-627. https://doi.org/10.1016/s22150366(20)30203-0
13. Higgins, J. T., \& Green, S. (2011). Cochrane handbook for systematic reviews of interventions. www.handbook.cochrane.org. Accessed 27 May 2021

14. Moher, D., Liberati, A., Tetzlaff, J., \& Altman, D. G. (2009). Preferred reporting items for systematic reviews and meta-analyses: The PRISMA statement. BMJ, 339, b2535. https://doi.org/10. 1136/bmj.b2535

15. PROSPERO 2020 CRD42020185995 (2020). https://www.crd. york.ac.uk/prospero/display_record.php?ID=CRD42020185995. Accessed 27 May 2021

16. Page, M. J., McKenzie, J. E., Bossuyt, P. M., Boutron, I., Hoffmann, T. C., Mulrow, C. D., Shamseer, L., Tetzlaff, J. M., \& Moher, D. (2021). The PRISMA 2020 statement: An updated guideline for reporting systematic reviews. $B M J, 372, \mathrm{n} 71$. https:// doi.org/10.1136/bmj.n71

17. Ouzzani, M., Hammady, H., Fedorowicz, Z., \& Elmagarmid, A. (2016). Rayyan-a web and mobile app for systematic reviews. Synthese Library, 5(1), 210. https://doi.org/10.1186/ s13643-016-0384-4

18. Weiss, D. S., \& Marmar, C. R. (1997). The impact of event scalerevised. In J. P. W. T. M. Keane (Ed.), Assessing psychological trauma and PTSD (pp. 399-411). The Guilford Press.

19. Lechien, J. R., Chiesa-Estomba, C. M., De Siati, D. R., Horoi, M., Le Bon, S. D., Rodriguez, A., \& Dequanter, D. (2020). Olfactory and gustatory dysfunctions as a clinical presentation of mild-to-moderate forms of the coronavirus disease (COVID19): A multicenter European study. European Archives of OtoRhino-Laryngology, 277(8), 2251-2261. https://doi.org/10.1007/ s00405-020-05965-1

20. Adhikari, S. P., Meng, S., Wu, Y. J., Mao, Y. P., Ye, R. X., Wang, Q. Z., Sun, C., Sylvia, S., Rozelle, S., Raat, H., \& Zhou, H. (2020). Epidemiology, causes, clinical manifestation and diagnosis, prevention and control of coronavirus disease (COVID-19) during the early outbreak period: A scoping review. Infectious Diseases of Poverty, 9(1), 29. https://doi.org/10.1186/s40249-020-00646-x

21. Lim, J., Jeon, S., Shin, H. Y., Kim, M. J., Seong, Y. M., Lee, W. J., Choe, K.W., Kang, Y.M., Lee, B. and Park, S.J. (2020). Case of the index patient who caused tertiary transmission of covid19 infection in Korea: The application of Lopinavir/Ritonavir for the treatment of COVID-19 infected pneumonia monitored by quantitative RT-PCR. Journal of Korean Medical Science, 35(6), https://doi.org/10.3346/jkms.2020.35.e79.

22. Liu, Y., Cao, L., Li, X., Jia, Y., \& Xia, H. (2020). Awareness of mental health problems in patients with coronavirus disease 19 (COVID-19): A lesson from an adult man attempting suicide. Asian Journal of Psychiatry, 51, 102106. https://doi.org/10. 1016/j.ajp.2020.102106

23. Daher, A., Balfanz, P., Cornelissen, C., Muller, A., Bergs, I., Marx, N., Müller-Wieland, D., Hartmann, B., Dreher, M., \& Müller, T. (2020). Follow up of patients with severe coronavirus disease 2019 (COVID-19): Pulmonary and extrapulmonary disease sequelae. Respiratory Medicine, 174, 106197. https://doi.org/10. 1016/j.rmed.2020.106197 [Research Support, Non-U.S. Gov't].

24. Kamal, M., Abo Omirah, M., Hussein, A., \& Saeed, H. (2020). Assessment and characterisation of post-COVID-19 manifestations. International Journal of Clinical Practice. https://doi.org/ 10.1111/ijcp. 13746

25. Townsend, L., Dyer, A. H., Jones, K., Dunne, J., Mooney, A., Gaffney, F., O’Connor, L., Leavy, D., O’Brien, K., Dowds, J., \& Sugrue, J. A. (2020). Persistent fatigue following SARS-CoV-2 infection is common and independent of severity of initial infection. PLoS ONE, 15(11), e0240784. https://doi.org/10.1371/journ al.pone.0240784 [Research Support, Non-U.S. Gov't].

26. Weerahandi, H., Hochman, K. A., Simon, E., Blaum, C., Chodosh, J., Duan, E., Garry, K., Kahan, T., Karmen-Tuohy, S. L., Karpel, H. C., \& Mendoza, F. (2021). Post-discharge health 
status and symptoms in patients with severe COVID-19. Journal of General Internal Medicine, 14, 14. https://doi.org/10.1007/ s11606-020-06338-4

27. Akter, F., Mannan, A., Mehedi, H. M. H., Rob, M. A., Ahmed, S., Salauddin, A., Hossain, M. S., \& Hasan, M. M. (2020). Clinical characteristics and short term outcomes after recovery from COVID-19 in patients with and without diabetes in Bangladesh. Diabetes \& Metabolic Syndrome, 14(6), 2031-2038. https://doi. org/10.1016/j.dsx.2020.10.016

28. Woo, M. S., Malsy, J., Pottgen, J., Seddiq Zai, S., Ufer, F., Hadjilaou, A., Schmiedel, S., Addo, M. M., Gerloff, C., Heesen, C., \& SchulzeZurWiesch, J. (2020). Frequent neurocognitive deficits after recovery from mild COVID-19. Brain Communications, 2(2), fcaa205. https://doi.org/10.1093/braincomms/fcaa205

29. Poncet-Megemont, L., Paris, P., Tronchere, A., Salazard, J. P., Pereira, B., Dallel, R., Aumeran, C., Beytout, J., Jacomet, C., Laurichesse, H., \& Lesens, O. (2020). High prevalence of headaches during Covid-19 infection: A retrospective cohort study. Headache, 60(10), 2578-2582. https://doi.org/10.1111/head.13923

30. Xiong, Q., Xu, M., Li, J., Liu, Y., Zhang, J., Xu, Y., \& Dong, W. (2021). Clinical sequelae of COVID-19 survivors in Wuhan, China: A single-centre longitudinal study. Clinical Microbiology and Infection, 27(1), 89-95. https://doi.org/10.1016/j.cmi.2020.09. 023

31. Chen, K. Y., Li, T., Gong, F. H., Zhang, J. S., \& Li, X. K. (2020). Predictors of health-related quality of life and influencing factors for COVID-19 patients, a follow-up at one month. Frontiers in Psychiatry Frontiers Research Foundation, 11, 668. https://doi. org/10.3389/fpsyt.2020.00668

32. Halpin, S. J., McIvor, C., Whyatt, G., Adams, A., Harvey, O., McLean, L., Walshaw, C., Kemp, S., Corrado, J., Singh, R., \& Collins, T. (2020). Postdischarge symptoms and rehabilitation needs in survivors of COVID-19 infection: A cross-sectional evaluation. Journal of Medical Virology. https://doi.org/10.1002/jmv.26368

33. Cavalagli, A., Peiti, G., Conti, C., Penati, R., Vavassori, F., \& Taveggia, G. (2020). Cranial nerves impairment in post-acute oropharyngeal dysphagia after COVID-19: A case report. European Journal of Physical and Rehabilitation Medicine, 17, 17. https:// doi.org/10.23736/S1973-9087.20.06452-7

34. Nalleballe, K., Reddy Onteddu, S., Sharma, R., Dandu, V., Brown, A., Jasti, M., Yadala, S., Veerapaneni, K., Siddamreddy, S., Avula, A., \& Kapoor, N. (2020). Spectrum of neuropsychiatric manifestations in COVID-19. Brain, Behavior, and Immunity, 88, 71-74. https://doi.org/10.1016/j.bbi.2020.06.020

35. Zheng, N., Zhang, T., Liu, Y., \& Zhu, X. Q. (2020). Investigation of the status of nurses returning to work after recovering from COVID-19 and influencing factors. Journal of Nursing Care Quality, 19, 19. https://doi.org/10.1097/NCQ.0000000000000521

36. Cai, X., Hu, X., Ekumi, I. O., Wang, J., An, Y., Li, Z., \& Yuan, B. (2020). Psychological distress and its correlates among COVID-19 survivors during early convalescence across age groups. American Journal of Geriatric Psychiatry, 28(10), 1030-1039. https://doi. org/10.1016/j.jagp.2020.07.003

37. Mazza, M. G., De Lorenzo, R., Conte, C., Poletti, S., Vai, B., Bollettini, I., Melloni, E. M., Furlan, R., Ciceri, F., Rovere-Querini, P., \& Benedetti, F. (2020). Anxiety and depression in COVID-19 survivors: Role of inflammatory and clinical predictors. Brain, Behavior, and Immunity, 89, 594-600. https://doi.org/10.1016/j. bbi.2020.07.037

38. Liu, K., Zhang, W., Yang, Y., Zhang, J., Li, Y., \& Chen, Y. (2020). Respiratory rehabilitation in elderly patients with COVID-19: A randomized controlled study. Complementary Therapies in Clinical Practice, 39, 101166. https://doi.org/10.1016/j.ctcp. 2020. 101166 [Randomized Controlled Trial].

39. Li, N., Han, L., Peng, M., Lv, Y., Ouyang, Y., Liu, K., Yue, L., Li, Q., Sun, G., Chen, L., \& Yang, L. (2020). Maternal and neonatal outcomes of pregnant women with COVID-19 pneumonia: A casecontrol study. Clinical Infectious Diseases. https://doi.org/10.1093/ $\mathrm{cid} / \mathrm{ciaa} 352$

40. Recalcati, S. (2020). Cutaneous manifestations in COVID-19: A first perspective. Journal of the European Academy of Dermatology and Venereology, 34(5), e212-e213. https://doi.org/10.1111/ jdv. 16387

41. Chen, F., Wang, X. D., Zhu, K. K., \& Hu, J. B. (2020). Investigation of the psychological status of suspected patients during the Coronavirus disease 2019 epidemic. Medicine, 99(38), e22260. https://doi.org/10.1097/MD.0000000000022260

42. Ahmed, H., Patel, K., Greenwood, D. C., Halpin, S., Lewthwaite, P., Salawu, A., Eyre, L., Breen, A., O'Connor, R., Jones, A., \& Sivan, M. (2020). Long-term clinical outcomes in survivors of severe acute respiratory syndrome and Middle East respiratory syndrome coronavirus outbreaks after hospitalisation or ICU admission: A systematic review and meta-analysis. Journal of Rehabilitation Medicine, 52(5), jrm00063. https://doi.org/10. 2340/16501977-2694 [Meta-Analysis Systematic Review].

43. Li, Z., Zheng, C., Duan, C., Zhang, Y., Li, Q., Dou, Z., Li, J., \& Xia, W. (2020). Rehabilitation needs of the first cohort of postacute COVID-19 patients in Hubei, China. European Journal of Physical and Rehabilitation Medicine, 56(3), 339-344. https:// doi.org/10.23736/s1973-9087.20.06298-x

44. Rabinovitz, B., Jaywant, A., \& Fridman, C. B. (2020). Neuropsychological functioning in severe acute respiratory disorders caused by the coronavirus: Implications for the current COVID-19 pandemic. Clinical Neuropsychologist. https://doi. org/10.1080/13854046.2020.1803408

45. Boals, A., Hayslip, B., Jr., Knowles, L. R., \& Banks, J. B. (2012). Perceiving a negative event as central to one's identity partially mediates age differences in posttraumatic stress disorder symptoms. Journal of Aging and Health, 24(3), 459-474. https://doi. org/10.1177/0898264311425089

46. Iaccarino, G., Grassi, G., Borghi, C., Carugo, S., Fallo, F., Ferri, C., Giannattasio, C., Grassi, D., Letizia, C., Mancusi, C., \& Minuz, P. (2020). Gender differences in predictors of intensive care units admission among COVID-19 patients: The results of the SARS-RAS study of the Italian Society of Hypertension. PLoS ONE, 15(10), e0237297. https://doi.org/10.1371/journal. pone. 0237297

47. Boland, B., \& Gale, T. (2020). Mental and behavioural disorders and COVID-19-associated death in older people. BJPsych Open, 6(5), e101. https://doi.org/10.1192/bjo.2020.87

48. Rutherford, C., Campbell, R., Brown, J. M., Smith, I., Costa, D. S. J., McGinnis, E., Wilson, L., Gilberts, R., Brown, S., Coleman, S., \& Collier, H. (2019). Comparison of generic and disease-specific measures in their ability to detect differences in pressure ulcer clinical groups. Wound Repair and Regeneration, 27(4), 396-405. https://doi.org/10.1111/wrr.12716

49. Li, Y.-K., Peng, S., Li, L.-Q., Wang, Q., Ping, W., Zhang, N., \& Fu, X. N. (2020). Clinical and transmission characteristics of Covid-19-a retrospective study of 25 cases from a single thoracic surgery department. Current Medical Science, 40(2), 295-300. https://doi.org/10.1007/s11596-020-2176-2

50. Wee, L. E., Chan, Y. F. Z., Teo, N. W. Y., Cherng, B. P. Z., Thien, S. Y., Wong, H. M., Wijaya, L., Toh, S. T., \& Tan, T. T. (2020). The role of self-reported olfactory and gustatory dysfunction as a screening criterion for suspected COVID-19. European Archives of Oto-Rhino-Laryngology, 277(8), 23892390. https://doi.org/10.1007/s00405-020-05999-5

Publisher's Note Springer Nature remains neutral with regard to jurisdictional claims in published maps and institutional affiliations. 